\title{
Sistemas atuais de cuidados e manutenção de lentes de contato
}

\author{
Current care and maintenance systems for contact lenses
}

\author{
César Lipener ${ }^{1}$ \\ Camila Baracat Mendina Ray ${ }^{2}$
}

Trabalho realizado no Setor de Lente de Contato do Departamento de Oftalmologia da Universidade Federal de São Paulo - UNIFESP.

${ }^{1}$ Mestre, Chefe do Setor de Lente de Contato da UNIFESP - São Paulo (SP) - Brasil.

${ }^{2}$ Médica colaboradora do Setor de Lente de Contato da UNIFESP - São Paulo (SP) - Brasil.

Endereço para correspondência: César Lipener. Rua Borges Lagoa, 368 - São Paulo (SP) CEP 04038-000 E-mail: lipener@uol.com.br

\section{RESUMO}

A correta manutenção das lentes de contato é fundamental para se obter sucesso e manter a continuidade de seu uso. É grande o número de pacientes que abandonam o uso de suas lentes por problemas que poderiam ser solucionados com tratamentos relativamente simples ou com uma orientação mais adequada. O mau uso das lentes, associado à má adaptação, contaminação, doenças oculares prévias e fatores ambientais, podem aumentar o número de infecções corneanas através da proliferação de microorganismos. O presente artigo visa apresentar as atualizações em relação aos cuidados e manutenção com as lentes de contato.

Descritores: Lentes de contato; Soluções para lentes de contato; Infecções oculares/etiologia; Infecções oculares bacterianas/prevenção \& controle; Infecções oculares parasitárias/ prevenção \& controle; Higiene; Desinfetantes

\section{INTRODUÇ̃̃̃O}

A importância da manutenção das lentes de contato (LC) é fundamental para se obter sucesso e manter a continuidade de seu uso, já que as complicações oculares devido à falta de obediência dos usuários em relação à manutenção e ao período de troca, em conjunto com a ausência de motivação estão entre as principais causas da desistência do paciente ${ }^{(1)}$.

É grande o número de pacientes que abandonam o uso de suas lentes por causa de problemas que poderiam ser solucionados com tratamentos relativamente simples ou com uma orientação mais adequada ${ }^{(2)}$.

Devido à falta de orientação, um fator decisivo para que algumas pessoas desistam de usar suas lentes é a manutenção inadequada ou o uso incorreto de produtos, como por exemplo, o soro fisiológico. O paciente deve saber que ao cuidar de suas lentes de maneira adequada, a chance de vir a desenvolver algum tipo de complicação será muito menor. Uma de nossas grandes preocupações é a adaptação muitas vezes inadequada, feita fora dos consultórios médicos, que pode ser responsável pelo aparecimento de problemas que impeçam, temporária ou definitivamente, o uso das lentes. Muito pacientes não sabem que a lente está em contato direto com a córnea e interfere em seu metabolismo e fisiologia.

O mau uso das lentes, associado à má adaptação, contaminação, doenças oculares prévias e fatores ambientais, podem aumentar o número de infecções corneanas através da proliferação de microorganismos como bactérias, fungos, parasitas, vírus, uma vez que o próprio uso da lente altera o mecanismo de defesa do olho ${ }^{(3)}$.

Além disso, os depósitos (orgânicos, inorgânicos e ambientais) acumulados durante o uso, propiciam o desenvolvimento de reações inflamatórias, infecciosas e imunológicas, além de desconforto e turvação visual ${ }^{(1)}$. 
As soluções multiuso vieram para facilitar o paciente no cuidado das LC, uma vez que limpeza, enxágüe e desinfecção são feitos com o mesmo produto. Suas macromoléculas reduzem a penetração do desinfetante na córnea, limitando seu acúmulo na matriz da lente. São componentes catiônicos poliméricos de alto peso molecular, agentes seletores de membrana e não eficazes contra amebas ${ }^{(4)}$.

\section{Sistemas de manutenção: componentes e funções ${ }^{(4-6)}$}

Para que os produtos destinados à conservação das lentes de contato possam ser efetivos em todas as etapas do processo de manutenção, eles devem conter, juntos ou isolados, em sua composição, diferentes classes de componentes, cada qual com sua função.

Surfactantes: ingredientes das soluções que têm como função a limpeza das LC.

Desinfectantes: atuam nos microorganismos da superfície das LC (ação antimicrobiana).

Preservativos: previnem a proliferação de microorganismos após a abertura dos frascos das soluções de limpeza das LC, evitando sua contaminação.

Agentes quelantes: reduzem depósitos de cálcio da superfície das LC.

Estabilizadores (solução tampão): mantêm o pH (boratos, fosfatos, citratos e trometamina).

Agentes de tonicidade: fazem com que a condição isotônica da solução se assemelhe à tonicidade da lágrima.

Agentes umectantes: melhoram o contato da LC com o olho diminuindo a tensão superficial, lubrificando e mantendo o conforto durante o uso.

Enzimas: atividade proteolítica, com a finalidade de diminuir a incidência de depósitos protéicos.

Agentes iônicos: prevenção de depósitos.

\section{Desinfecção e preservativos ${ }^{(4-6)}$}

Ao mesmo tempo que devem proporcionar um controle efetivo contra os microorganismos, os produtos devem, também, não ser tóxicos à superfície ocular.

Por este motivo, o timerosal e a clorhexidina foram praticamente abandonados, já que, freqüentemente, causavam hipersensibilidade e reações tóxicas aos pacientes.

Timerosal: derivado do mercúrio, eficaz contra gram negativos e fungos, principalmente em conjunto com EDTA.

Clorhexidina: biguanida eficaz contra gram positivos. Por sua carga positiva é atraída pela carga negativa da LC, tornando-a amarelada.

Ácido ascórbico: presente nas soluções salinas. Fraco agente antimicrobiano que necessita do EDTA para se tornar eficaz. Se usado em desinfecção térmica pode causar reação de hipersensibilidade e amarelamento das LC.

EDTA (ethylenediaminotetra-acetato ou edetato dissódico): corresponde a qualquer sal de ácido edetático. Agente quelante que potencializa a atividade de antimicrobianos catiônicos, como cloreto de benzalcônio e clorexidina, provavelmente que redução de cálcio e magnésio da membrana celular microbiana e aumento da permeabilidade celular. É efetivo contra Pseudomonas aeroginosa.

Álcool isopropílico: alta eficácia antimicrobiana e toxicidade.

Polyquad (polyquaternium-1) 0,001\%: polímero catiônico solúvel em água e mistura água/álcool. Composto quaternário de alto peso molecular previne a absorção nos poros das lentes hidrofílicas. Não impede o crescimento de células corneanas humanas e tem ação antimicrobiana.

Dymed (poliaminopropil biguanida) 0,00005\%: polímero formado por unidades repetidas de biguanida (carga positiva) separadas por uma cadeia de seis carbonos. Ação semelhante à clorhexidina, com moléculas maiores e sem benzina. Desintegra o microorganismo, sendo muito seletivo suas membranas (carga negativa).

Tris-Chem (polihexametileno de biguanida - PHMB): amplo espectro e baixa toxicidade.

\section{Etapas para manutenção das lentes de contato ${ }^{(1,4,6)}$}

Ao contrário do que ocorria há alguns anos, quando os usuários tinham que limpar suas lentes com inúmeros produtos diferentes ou até fervê-las, a manutenção tornou-se, atualmente, mais simples e prática, o que pode fazer o paciente aderir mais facilmente aos procedimentos ${ }^{(7)}$.

Toda lente, independente de ser rígida ou gelatinosa, descartável ou convencional, deve, a princípio, passar por um processo de manutenção que inclua limpeza diária, desinfecção e retirada dos depósitos de proteínas.

Estas são as principais recomendações que devem ser explicadas e, sempre que possível, fornecidas por escrito. É importante também checar nos retornos se o paciente está seguindo as recomendações.

\section{1 - Limpeza do estojo}

No mínimo uma vez por semana com água quente sem sabão. Deixar secar ao ar e guardar fechado. Ideal seria o uso de estojo descartável, caso contrário, trocá-lo a cada seis meses.

\section{2 - Higiene das mãos, olhos e anexos}

Lavar as mãos com sabonete neutro e secá-las com toalha que não solte fiapos.

\section{3 - Limpeza das lentes de contato}

Deve ser feita logo após a retirada, com leve fricção. As soluções para limpeza removem os resíduos e diminuem o número de microorganismos. Existem três tipos de limpadores: os surfactantes, os enzimáticos e os oxidantes.

Os limpadores surfactantes podem ser iônicos (aniônico, catiônico ou anfotérico) ou não iônicos. Os não iônicos (tiloxapol, propilenoglicol, álcool polivinílico, miranol, poloxâmero, sais de sódio, tween 21) são usados com freqüência porque apresentam boa compatibilidade, estabilidade e baixa toxicidade. $\mathrm{O}$ surfactante possui forte ligação com substâncias gordurosas e com a água, que ao correr leva a gordura e limpa a superfície. Sua ação pode ser potencializada pela adição de partículas abrasivas ou poliméricas. 
Aparelhos que submetem a lente ao ultra-som podem ser eficazes em complementar a limpeza mecânica das lentes.

\section{4 - Enxágüe}

Remove os resíduos dos produtos usados. Nunca usar água de torneira, filtrada, mineral ou destilada, e sim solução salina isotônica (em pequenos frascos para diminuir o risco de contaminação) ou solução multiuso. Algumas soluções não necessitam de enxágüe.

\section{5 - Desinfecção}

É eficiente contra a maioria dos microorganismos mas não com os esporos. Pode ser térmica, química oxidativa (peróxido de hidrogênio a $3 \%$ ) ou química não oxidativa (soluções multiuso).

A desinfecção térmica necessita de temperatura de $80^{\circ} \mathrm{C}$ ou mais por, no mínimo, 10 minutos, em solução salina. Eficaz contra qualquer microorganismo, inclusive Acanthamoeba, no entanto encurta a vida útil das LC.

O peróxido de hidrogênio a 3\% é eficiente contra Pseudomonas aeroginosa e Acanthamoeba, sendo necessárias duas horas para as amebas, o que pode alterar a estruturas da LC. Apesar de muito eficaz, pode causar irritação e necessita de neutralização ou diluição.

As soluções multiuso (ou multi propósito) proporcionam uma maior vida útil para a lente, além de ser mais cômodas para os pacientes, facilitando a adesão em relação à conservação das lentes. Os produtos disponíveis no Brasil são: Complete Comfort Plus ${ }^{\circledR}$ (Allergan), OPTI-FREE ${ }^{\circledR}$ Replani$\mathrm{SH}^{\circledR}$ (Alcon), ReNu Plus ${ }^{\circledR}$ (Bausch \& Lomb) e SOLO-care ${ }^{\circledR}$ (Ciba Vision). Para as rígidas gás permeáveis, Boston Simplicity ${ }^{\circledR}$ (Bausch \& Lomb) e Unique $\mathrm{pH}^{\circledR}$ (Alcon).

Com uso mais restrito e menos fundamentado, existem opções como o ultra-som, congelamento e luz ultravioleta para desinfecção.

\section{6 - Tratamento enzimático}

Remoção de depósitos protéicos através de sistema de enzima simples (papaína), sistema de ação multi enzimático (pancreatina) e subtilisina A. Os produtos disponíveis são: Hydrocare $^{\circledR}$ (Allergan), Polyzym ${ }^{\circledR}$ (Alcon), Supraclens ${ }^{\circledR}$ (Alcon), Ultrazyme ${ }^{\circledR}$ (Allergan) e FizziClean ${ }^{\circledR}$ e ReNu ${ }^{\circledR} 1$ Step $^{\mathrm{TM}}$ (Bausch \& Lomb).

\section{7 - Lubrificação}

Pode ser feita antes, durante e após o uso das LC. As lentes tendem a ficar ressecadas após longos períodos de uso, principalmente em épocas ou locais de clima mais seco. Seu uso é fundamental em pacientes portadores de olho seco.

\section{Lentes descartáveis}

As lentes usadas por mais de 30 dias e que não forem descartadas devem passar também por estas três etapas. As que forem descartadas em um prazo de até 15 dias podem dispensar a desproteinização, ou em outras situações a critério médico. Baseado no exame ocular, pode-se optar por diminuir o perío- do de descarte de uma lente, bem como alterar o esquema de manutenção, mais um motivo para que se faça o acompanhamento periódico dos usuários.

\section{Reações de sensibilidade}

As reações tóxicas mais comuns são causadas por cloreto de benzalcônio, clorhexidina, enxágüe inadequado da solução limpadora, resíduo de limpador enzimático e contaminação das LC. Ocorre dentro de minutos ou horas do início do uso da LC. O timerosal é a causa mais freqüente de reação alérgica, que pode levar semanas ou meses para se manifestar ${ }^{(1)}$.

É muito importante orientar os pacientes quanto aos riscos causados pela substituição do produto de limpeza e desinfecção pelo soro fisiológico. Este não limpa nem retira os depósitos de proteínas das lentes, deixando-as mais sujas, contaminadas e menos confortáveis. Além disso, pode ser um ambiente propício à proliferação de microorganismos que podem comprometer a saúde ocular. Outro problema do soro é sua cristalização, ou seja, o sal (cloreto de sódio) cristaliza-se e ao aderir às lentes pode provocar desconforto e diminuir o tempo de vida útil das mesmas. Na verdade, a maior causa de reações tóxicas em usuários de LC é o uso do soro fisiológico, pela presença de preservativos químicos em sua composição.

\section{ATUALIZAÇÃ̃O}

A influência das etapas de manutenção e de seus produtos no conforto e na segurança em relação à prevenção de complicações, principalmente as infecciosas, é abordada com freqüência na literatura. Vários estudos comparam produtos existentes no mercado, mas devem ser vistos com muita atenção, já que vários, talvez a maioria, sejam patrocinados ou mesmo realizados pelos próprios fabricantes.

Alguns autores ${ }^{(8)}$ mostram resultados que sugerem a possibilidade do uso freqüente de algumas soluções multi-propósito poder, através de mecanismos de toxicidade, causar uma quebra da barreira epitelial da córnea, aumentando o risco de ceratites microbianas em usuários de lentes gelatinosas.

Para outros autores ${ }^{(9)}$, a formulação do produto multi-uso ideal passa pelo dilema entre eficácia antimicrobiana, toxicidade e compatibilidade/conveniência.

Vários produtos eficientes foram abandonados ao longo dos anos por serem excelentes para desinfecção mas apresentarem reações de toxicidade, que podem afetar até um terço dos usuários de lentes, incluindo hiperemia conjuntival, folículos, ceratite puntata, entre outras.

Recentemente, houve um surto em vários países, principalmente nos Estados Unidos da América (EUA), de ceratite fúngica em usuários de lentes gelatinosas, tendo havido provável relação com certas soluções multi-uso. O tipo de lente usada também foi uma preocupação, motivando alguns trabalhos para esclarecer melhor o ocorrido.

$\mathrm{O}$ estudo de um trabalho ${ }^{(10)}$ teve como objetivo avaliar e comparar a atividade antifúngica residual de soluções multi- 
propósito (ReNu MultiPlus ${ }^{\circledR}$ e MoistureLoc ${ }^{\circledR}$ e OPTI-FREE ${ }^{\circledR}$ RepleniSH ${ }^{\circledR}$ ) contaminadas, e sua relação com o material da lente, variando a hidratação e a carga iônica, para avaliar a eficácia da inibição destas substâncias na prevenção da colonização destas lentes pelos fungos.

No surto de Fusarium recentemente visto nos EUA, 53\% dos pacientes usavam lentes do grupo IV, 38\% silicone hidrogel, $5 \%$ grupo I e $1 \%$ grupo II.

Este estudo mostrou que os produtos não foram eficazes em prevenir a colonização das lentes.

Outra grande preocupação é, sem dúvida, o aumento nos números de ceratite por Acanthamoeba em usuários de LC. Em relação a este assunto, Acharya ${ }^{(11)}$ comenta que estes surtos ainda não foram bem explicados e outros fatores de risco, além das soluções multi-uso implicadas, podem estar envolvidos. Independente disso, é fundamental que se enfatize ao paciente o uso correto das lentes bem como de sua manutenção. Os pacientes devem saber dos riscos envolvidos no uso das lentes durante o sono e saber que as mesmas devem ser retiradas em caso de qualquer irritação, sinal ou sintoma atípico. Quando diante de um caso de ceratite, o médico deve sempre lembrar de etiologias não bacterianas e o uso de corticóides nestes casos não deve ocorrer de forma empírica, já que pode haver o envolvimento de protozoários ou fungos. O autor espera ainda que estes recentes surtos de ceratite por Fusarium permitam que haja maior entendimento sobre os fatores de risco envolvidos, facilitando sua prevenção e tratamento.

Outro estudo ${ }^{(12)}$, a respeito da relação de produtos com o surto de ceratite, relata que o produto da AMO, o Complete ${ }^{\circledR}$ MoisturePlus ${ }^{\mathrm{TM}}$ Multi-Purpose é relacionado de forma independente com a ceratite por Acanthamoeba em usuários de lentes gelatinosas. Entretanto, isso não explica todos os casos, sugerindo o envolvimento de outros fatores de risco bem como de medidas de higiene, que devem ser melhor explorados e que serão úteis na prevenção destes tipos de complicação.

Um outro assunto muito controverso, é a divulgação pelos fabricantes de produtos, de que não é mais necessária a limpeza das lentes através da fricção digital, bem como o uso da desproteinização enzimática. Alguns autores ${ }^{(13)}$ comentam que relatos recentes sobre ceratites infecciosas em usuários de LC mostram o envolvimento de vários patógenos, entre os quais Acanthamoeba e fungos, como o Fusarium. Não se sabe ao certo o que levou ao aumento na incidência de infecções por agentes que até então raramente estavam envolvidos nestes casos. Algumas explicações sugerem ineficácia das soluções multi-uso contra certos agentes, cuidados e higiene inadequados com as lentes e estojos, incluindo aí a eliminação da etapa de fricção digital. A introdução de novos materiais pode também facilitar a aderência de certos patógenos e também podem influir.

A análise de vários estudos, apesar de opiniões conflitantes na literatura, sugere que a conveniência de simplificar a manutenção eliminando a fricção pode ter conseqüências em função da maior aderência de certos agentes à superfície da lente. Por isso seria prudente restabelecer a importância desta etapa.

\section{CONSIDERAÇÕES FINAIS}

A manutenção correta das lentes é essencial na prevenção de complicações infecciosas, tóxicas e alérgicas, bem como para o conforto de seu uso. Como já frisamos anteriormente, é grande o número de pacientes que abandonam as lentes por complicações causadas por falta de cuidados ou produtos inapropriados ${ }^{(14)}$.

O uso correto das soluções, juntamente com treinamento e educação do paciente e a orientação médica, são fundamentais para o sucesso no uso das lentes de contato. Portanto, também é função do médico participar de forma ativa na orientação sobre a manutenção de lentes de seus pacientes, bem como estar atento às eventuais intercorrências que podem estar relacionadas com cuidados inadequados, evitando assim que o paciente abandone o uso das lentes ${ }^{(15)}$.

\section{ABSTRACT}

The proper maintenance of contact lenses is crucial for their success and to maintain the continuity of their use. Many patients abandon the use of their lenses due to problems that could be solved with relatively simple treatments. The misuse of lenses, coupled with poor adjustment, contamination, eye disease and environmental factors may increase the number of corneal infections through the proliferation of microorganisms. This article aims to provide contact lens care and maintenance updates.

Keywords: Contact lenses; Contact lens solutions; Eye infections/etiology; Eye infections bacterial/prevention \& control; Eye infections parasitic/prevention \& control; Hygiene; Disinfectants

\section{REFERÊNCIAS}

1. Coral-Ghanem C, Kara-José N. Manutenção das lentes de contato. In: CoralGhanem C, Kara-José N. Lentes de contato na clínica oftalmológica. 2 ${ }^{\underline{a}}$ ed. Rio de Janeiro: Cultura Médica; 1998. p.113-28.

2. Vieira S. Pequenos cuidados, prevenção garantida. Universo Vis. 2005;22:10-6

3. Robertson DM, Petroll WM, Jester JV, Cavanagh HD. The role of contact lens type, oxygen transmission, and care-related solutions in mediating epithelial homeostasis and pseudomonas binding to corneal cells: an overview. Eye Contact Lens. 2007;33(6 Pt 2):394-8; discussion 399-400.

4. Moreira SMB, Moreira H, Moreira LB. Limpeza e assepsia das lentes hidrofílicas. In: Moreira SMB, Moreira H, Moreira LB. Lente de Ccntato. 3a ed. Rio de Janeiro: Cultura Médica; 2004. p.187-97.

5. Moreira SMB, Moreira H, Moreira LB. Limpeza e assepsia das lentes rígidas. In: Moreira SMB, Moreira H, Moreira LB. Lente de contato. 3a ed. Rio de Janeiro: Cultura Médica; 2004. p.119-22.

6. Coral-Ghanem C, Stein HA, Freeman MI. Manutenção e manuseio das lentes de contato. In: Coral-Ghanem C, Stein HA, Freeman MI. Lentes de contato do 
básico ao avançado. 2a ed. Joinville: Soluções e Informática. 2005. p.18-46. 7. Rakow PL. Current contact lens care systems. Ophthalmol Clin North Am. 2003;16(3):415-32.

8. Imayasu M, Shiraishi A, Ohashi Y, Shimada S, Canavagh HD. Effects of multipurpose solutions on corneal epitelial tight junctions. Eye Contact Lens. 2008;34(1):50-5.

9. Papas EB, Carnt N, Willcox MD, Holden BA. Complications associated with care products use during silicone daily wear of hydrogel contact lens. Eye Contact Lens. 2007;33(6 Pt 2):392-3; discussion 399-400.

10. Ide T, Miller D, Alfonso EC, O'Brien TP. Impact of contact lens group on antifungal efficacy of multipurpose disinfecting contact lens solutions. Eye Contact Lens. 2008;34(3):151-9.
11. Acharya NR. Parasites on the rise: a new epidemic of Acanthamoeba keratitis. Am J Ophthalmol. 2007;144(2):292-3.

12. Joslin CE, Tu EY, Shoff ME, Booton GC, Fuerst PA, McMahon TT, et al. The association of contact lens solution use and Acanthamoeba keratitis. Am J Ophthalmol. 2007;144(2):169-80.

13. Butcko V, McMahon TT, Joslin CE, Jones L. Microbial keratitis and the role of rub and rising. Eye Contact Lens. 2007;33(6 Pt 2):421-3; discussion 424-5.

14. Moreira SMB, Moreira H, Moreira LB. Fatores de insucesso na adaptação de lentes de contato. In: Moreira SMB, Moreira H, Moreira LB. Lente de Contato. $3^{\underline{a}}$ ed. Rio de Janeiro: Cultura Médica; 2004. p.355-8.

15. Foulks GN. Prolonging contact lens wear and making contact lens wear safer. Am J Ophthalmol. 2006;141(2):369-73. 